REVIEW

\title{
Domestic violence in emergency medicine patients
}

\author{
A Boyle, S Robinson, P Atkinson
}

Emerg Med J 2004;21:9-13

Domestic violence is an important public health issue. This review seeks to inform doctors who care for patients who have suffered domestic violence.

See end of article for authors' affiliations .....................

Correspondence to: $\operatorname{Dr}$ A Boyle, Department of Psychiatry, Box 189, Addenbrooke's Hospital Hills Road, Cambridge, UK

boylea@doctors.org.uk

Accepted for publication 17 June 2003
D omestic violence is a not a new problem, prior to 1824 a husband was legally allowed to batter his wife, provided the stick he used was smaller in diameter than his thumb, thus giving rise to the expression "rule of thumb." ${ }^{1}$ The UK Department of Health estimates that women on average experience 35 episodes of domestic violence before seeking help. ${ }^{2}$ Many of these women will present to emergency departments as a consequence of this abuse. This review is intended to inform clinicians who will care for these patients. The American College of Emergency Physicians acknowledges the importance of domestic violence and advocates the detection of domestic violence, and BAEM has published guidelines on management of domestic violence. ${ }^{34}$ More recently, the British government has launched a number of initiatives to help victims of domestic violence. $^{2}$

\section{BACKGROUND}

There is no accepted definition of domestic violence in the medical literature and there is wide variation in the terms used to describe the phenomenon; abuse, intimate partner abuse, interpersonal violence, wife battering, or violence against women are all in common use. Terms such as "wife beating" and "violence against women" are unsatisfactory as they imply that abuse is only man against woman. While most domestic violence is directed at women by their male partners, a significant proportion of domestic violence occurs against men in heterosexual, and against men and women in homosexual relationships. ${ }^{5}$ It is not possible from the literature to identify whether male victims of domestic violence are purely victims or abusers whom have been assaulted back by their victims. The literature does not agree in what defines the perpetrator of domestic violence, whether a current or ex-partner, a cohabitant or family member. For instance, a North American community survey required that the perpetrator had intimate relations with the victim for more than three months, ${ }^{6}$ while a British survey of psychiatric in-patients defined the perpetrator as "someone who might have been expected to be supportive". ${ }^{7}$ There is also great disparity in what constitutes "violence". Significant proportions of the public and medical community restrict the term violence to physical assault.
While this definition of violence is usually valid for violence perpetrated by a stranger, usually resulting from conflict, it has less validity for assaults perpetrated by an intimate partner. Violence within a relationship usually results from coercion and comprises controlling behaviours, verbal abuse, and economic control, in addition to physical assault. This is acknowledged by the World Health Organisation who define violence as "...the intentional use of physical force or power, threatened or actual ...that either results in, or has a high likelihood of resulting in injury, death, psychological harm, maldevelopment, or deprivation". ${ }^{8}$ The British Crime Survey defines "domestic" as "all intimate relationships, whether or not there has been cohabitation' and 'violence' as 'woundings and common assault." This does not include nonphysical manifestations of domestic violence because this survey is concerned with those acts that fit the legal definition of a crime.'

\section{Incidence and prevalence}

It is realistic to assume that the incidence and prevalence rates derived from interview based surveys are underestimates as studies relating to domestic violence are invariably hampered by the reluctance of victims to disclose information. The array of definitions used in the literature mean that comparing rates across and within populations is not reliable or valid. In one cross sectional study, $11.7 \%$ of women visiting a variety of American emergency departments were there because of acute injury or stress related to domestic violence. ${ }^{10}$ The women suffering acute domestic violence had no significant difference in diagnosis compared with women who were not suffering domestic violence. Two per cent of women presented with injuries directly attributable to acute domestic violence. The most striking finding in this paper was the lifetime prevalence rate for domestic violence of $54.2 \%$ in women attending emergency departments. A cross sectional study performed in the UK, using identical methods, found that about $1 \%$ of patients attending an emergency department were a direct result of domestic violence. The lifetime prevalence rate for domestic violence in this population was $22 \% .^{11}$

Similar figures have been replicated in other surveys. ${ }^{12}$ A prospective survey of all assault victims attending a Scottish department over two months found 19 women who had been assaulted. ${ }^{13}$ This department is recorded as

Abbreviations: PVS, partner violence scale; ISA, index spouse abuse; CTS, conflict tactics scale 
seeing 60000 patients a year. A British prospective study on assaults of all causes attending over a 34 day period found 60 women who had been assaulted, of which 28 had been assaulted at home. ${ }^{14}$ Retrospective studies usually indicate a low incidence of self reported domestic violence. In a retrospective review of markers for domestic violence in a British hospital, 100 women self reported domestic violence out of 21121 , less than $0.5 \% .{ }^{15}$ The difference between the American studies and the British studies can in part be explained by differences in methods of reporting and the definitions used, for instance the American studies were not restricted to injuries attributable to acute domestic violence.

There is wide variation in prevalence rates reported by Australian studies. A figure of $25 \%$ was reported by one survey, however the authors did not interview women after midnight and had less than a $50 \%$ response rate. ${ }^{16}$ A more robust Australian study indicated that $30.7 \%$ of women and $15.5 \%$ of men had experienced adult domestic violence. ${ }^{17}$ The main message of these Australian and American papers is that while acute injury as a result of domestic violence is comparatively uncommon, the prevalence of domestic violence is high in emergency department populations. Whether this differs from the results from community surveys is difficult to say with certainty, the British Crime Survey reports a lifetime prevalence of $26 \%$ among women and $17 \%$ among men and annual prevalence of $5.9 \%$ and $4.9 \% .{ }^{9}$ These figures are broadly consistent with the results from an emergency department survey that used a similar definition of domestic violence. ${ }^{11}$ It seems that $5 \%$ of our patients are likely to have experienced domestic violence in the preceding year.

\section{Demographics}

Most victims of domestic violence are women. However, domestic violence is not purely a male to female event. An Australian study indicated that $15.5 \%$ of men attending an emergency department had experienced domestic violence at some point in their life, about half that of women in the same study. ${ }^{18}$

A case-control study of women who reported injury as a result of domestic violence, found associations between domestic violence and; lack of education, alcohol misuse, unemployment, low income, and recreational drug use. ${ }^{19}$

It was previously believed that pregnant women were at greater risk of both minor and severe violence than nonpregnant women, however when controlled for age this association was found to be spurious. ${ }^{20}{ }^{21}$ Youth is certainly a risk factor for recent domestic violence and more than one author has suggested that domestic violence is more common post-partum than pre-natally. ${ }^{22}{ }^{23}$ The severity of domestic violence seems to escalate during pregnancy. ${ }^{23}$

\section{Consequences of domestic violence}

Domestic violence is increasingly being recognised as a significant public health issue. Domestic violence is associated with more than just the physical injury. There is cohort evidence that female victims of domestic violence have increased use of all forms of medical care, not just trauma and mental health services. ${ }^{24}$ This study demonstrated an admission rate nearly four times higher in the battered group. A psychiatric diagnosis was made more commonly in the battered group, particularly alcoholism, depression, and deliberate self harm. These authors also identified that battered women were more likely to present with multiple and poorly defined complaints. They suggest that domestic violence should be considered in women who present with multiple poorly defined complaints. A significant association between reporting domestic violence and deliberate self harm has been identified in a number of cross sectional studies. ${ }^{10} \mathrm{It}$ is unclear whether this association is causal. It is plausible that being assaulted by an intimate partner is a depressing event and can lead to deliberate self harm, however it is equally plausible that there are personality traits that are associated with deliberate self harm, which also confer an increased risk of entering an abusive relationship.

An American study identified that emergency department use was common in the two years before murder by a partner. $^{25}$ In the USA, a spouse or intimate partner perpetrated $33.6 \%$ of female homicides, while less than $8 \%$ of murders of men were perpetrated by a spouse or intimate partner. ${ }^{26}$ In Maryland, USA, homicide is now the leading cause of maternal mortality and accounts for $20 \%$ of deaths in pregnancy, though it is not clear how many of these homicides were perpetrated by an intimate partner. ${ }^{27}$

The murder rate in the USA is considerably higher than most of the developed world and whether findings from the USA apply to the UK is unclear. ${ }^{28}$

Murder is a rare event in the UK. In 2001 there were 832 homicides in England and Wales, 582 occurred in men and 32 $(5.5 \%)$ of these were perpetrated by a partner or ex-partner. Altogether 250 homicides occurred in women and 116 $(46.4 \%)$ of these were perpetrated by a partner or an expartner. ${ }^{29}$ The latest Confidential Enquiry into Maternal Death in the United Kingdom found that of the 378 deaths that had occurred in the three years 1997 to 1999, 12\% of women had reported domestic violence before death. ${ }^{30}$

The children of the victim have also been shown to suffer. There is evidence that children who live with physically violent parents are prone to being abused by both parents though these studies are difficult to conduct. ${ }^{31}{ }^{32}$ Mothers who had been assaulted in front of their children felt that their children emotionally suffered as a result. ${ }^{33}$ A study in Bristol found that 9 of 79 female victims of assault presenting to an A\&E department were listed on the child protection register. Though this is a small study, this is disproportionately high compared with the general population. ${ }^{34}$

\section{Injury patterns}

There are injuries and injury patterns that have a high positive predictive value for child abuse. There are no such injuries or patterns that reliably predict domestic assault. Head, face, and neck injuries seem to be more common. ${ }^{35-37}$ However, the predictive values, specificities, sensitivities of these injuries are probably too low to reliably identify or exclude patients. Repeated attendance is more common. ${ }^{36}$ This study also noted a noticeable difference in the time of day at which women presented for treatment of assault compared with those who presented with unintentional injuries, assaulted women were more likely to present after $6 \mathrm{pm}$ and before $6 \mathrm{am}$. This study also indicated that victims of domestic violence might have comparatively minor injuries, which do not require much treatment. Multiple injuries may also be more common. ${ }^{15}$ However, despite these findings, a woman who presents at night, with injuries to the head and neck, many hours after the event and has had previous attendances with injuries is still more likely not to have been assaulted by an intimate partner rather than to have been assaulted by a partner.

\section{Screening for domestic violence}

It seems that history taking and clinical examination is unsatisfactory for diagnosing domestic violence. Screening has been suggested for every patient who presents to an emergency department. This view is supported by numerous US agencies, including the US Department of Health and Human Services and the American Medical Association. ${ }^{38} 39$ The Department of Health in England advocates that "routine enquiry" — that is, screening-for all women should be considered by healthcare professionals. ${ }^{2}$ Whether domestic violence fulfils the criteria for screening is controversial. ${ }^{40}$ 
Domestic violence is certainly an important condition, and certainly carries significant health consequences. Screening is probably acceptable to most patients attending an emergency department. ${ }^{41}$ It is less clear whether screening is acceptable to physicians and nurses. It could be argued that we do not know enough about the natural history of domestic violence to institute formal screening programmes. We also do not know enough about the effectiveness of the interventions and organisations designed to help identified victims of domestic violence. Indeed, most studies of interventions to reduce domestic violence do not consider important outcomes, such as reduced exposure to violence. ${ }^{40}$ Many of the organisations that help victims are charitably run and whether they could cope with the increased workload that a screening programme would cause is unclear. Once domestic violence has been identified, there is a risk that interventions may provoke further violence, specific measures need to be in place to prevent this. At present it does not seem that there is enough evidence to support screening all patients or even all women attending emergency departments for domestic violence. ${ }^{40}$

\section{IMPROVING DETECTION OF DOMESTIC VIOLENCE}

While the evidence does not support screening for domestic violence, it is still important that emergency physicians know how to create the opportunity of a patient disclosing domestic violence, so that self reported victims of domestic violence can be offered help. This process is distinct from a screening programme. Ideally all consultations should take place in a private room with, initially, only the patient and the doctor. This simple step is not widely applied; often the partner is encouraged to be part of the consultation process. If exclusion of the partner became standard, then the partner who insisted on staying with his or her partner would look more suspicious. This may be particularly difficult in cases where the patient does not speak English, is confused or where a witnessed history is vital, for example, syncope. It is inappropriate to rely on family members to interpret, official interpreters should be used where possible. The Confidential Enquiry in Maternal Deaths recommends that every woman is interviewed alone at least once during the antenatal period and this sensible step could be extended to emergency medicine.

Simple, direct, non-judgemental questions are the best way to inquire about domestic violence if this is felt appropriate. The partner violence scale (PVS) consists of three questions that have been compared with both the index spouse abuse (ISA) and the conflict tactics scale (CTS), two validated measures of domestic violence.

The first question proved to be nearly as useful as all three questions at identifying victims. The sensitivity of the PVS compared with the ISA was $65 \%$; specificity was $80 \%$ with a positive predictive value of $51 \%$. The sensitivity, specificity, and positive predictive values of the PVS compared with the CTS were comparable, if slightly better. ${ }^{42}$

In one hospital in the USA the rate of detection of domestic violence among female patients increased from $1 \%$ to $18 \%$ after patient charts were modified to include screening

\section{Box 1 The partner violence scale}

- Have you been hit, kicked, punched, or otherwise hurt by someone within the past year?

- Do you feel safe in your current relationship now?

- Is there a partner from a previous relationship who is making you feel unsafe now? questions for domestic violence. Interestingly women were more likely to disclose domestic violence to female nurses despite the male nurses asking the same proportion of patients. Screening occurred less often at night, with sicker patients, and with patients presenting with a primary psychiatric diagnosis. ${ }^{43}$

There are many barriers to physicians inquiring about domestic violence. ${ }^{44}$ The erroneous assumption that domestic violence occurs exclusively in women from lower socioeconomic classes leads many physicians not to consider domestic violence in patients from higher socioeconomic classes. Many doctors may feel uncomfortable asking questions about abusive relationships. We personally and anecdotally find the question "We know that violence at home is a problem for many people, is there anyone who is hurting you in someway?" useful. Time constraints may encourage doctors to focus in on the primary problem, rather than "open Pandora's box".

The Greet and Treat system will do little to encourage staff to explore the possibility of domestic violence. Feelings of helplessness and ignorance of what to do with a patient who discloses domestic violence hinders direct questioning. There is also a fear of offending the patient and undermining the doctor-patient relationship. This can be helped by a "business as usual" approach. A number of states in the US have mandatory reporting laws when domestic violence is disclosed to a physician. These are controversial and there are concerns that physicians may be less likely to inquire about domestic violence and victims are less likely to disclose. These laws probably do not increase the reporting of domestic violence. ${ }^{45}$ Some experts feel that merely asking a question should be regarded as a meaningful step, as it may indicate to a victim that help is available. It may also reduce the feeling of helplessness that occurs in victims. ${ }^{46}$

\section{Management of an identified victim of domestic violence}

As always the priority is to treat the physical injury. Injuries should be meticulously recorded and photographs taken if appropriate. Specific inquiry should be made about the presence and age of children living in a violent household. Attempts should be made to find out whether any children are at risk of abuse, both by direct questioning and use of the child protection register. Any concerns for child safety should lead to the activation of local child protection procedures.

It should be explained to the victim that domestic violence is unacceptable and against the law. Police contact should be offered while in the comparative safety of the emergency department. It is much easier to contact the police from the emergency department than a household that is shared with the perpetrator. Refusal of police contact is common and may frustrate medical staff. The reasons for declining to involve the police are often complex and should be explored. Common reasons include low self esteem and self blame, concerns about children, and a fear that action will lead to further violence. There is some evidence that abused women who involve the police have lower rates of violence than those who do not, though it is not clear whether this is due solely to the actions of the police. ${ }^{47}$ There is randomised controlled trial evidence that advocacy services have a role in reducing levels of violence, though whether this American evidence applies to a UK population is unclear. ${ }^{48}$ There is also cohort evidence that community protection orders in the US are associated with lower rates of abuse, although again the external validity of a study conducted in the US to British practice is limited. ${ }^{49}$

A US retrospective cohort study found that permanent protection orders was associated with a reduced risk of reporting subsequent domestic violence when compared with 
victims of domestic violence..$^{50}$ This association may be due, in part, to confounding variables. Women who sought protection orders were more likely to misuse drugs and alcohol and less likely to be living with their assailant.

There are a number of agencies that provide help for victims of domestic violence, Women's Aid (http://www. womensaid.org.uk) and Victim Support (http://natiasso03. uuhost.uk.uu.net/) are probably the best known. These do not require police involvement. Women's Aid maintains shelters across Britain, but also can advise on how to help a woman in abusive relationships before they leave. They also lobby governmental agencies to improve the rights of women. Victim Support aims to support any victim of crime and has an interest in domestic violence.

Provision for victims of domestic violence varies from region to region. At the very least a leaflet should be available, containing the telephone numbers of these organisations and useful advice. We have found that leaflets placed in the women's toilets disappear very quickly. Within some Australian emergency departments there are resident social workers that can assist at the point of contact ( $\mathrm{J}$ Vinnen, personal communication)

\section{Local responses to domestic violence}

Most regions have domestic violence forums, which are collections of representatives from interested bodies. For instance, our local domestic violence forum has a judge, a solicitor, a probation officer, community midwives, social workers, police officers from the family unit, an emergency nurse, council housing officers, and representatives from Victim Support and Women's Aid. The aim of these forums is to coordinate agency responses to domestic violence. The effectiveness of these forums has not been evaluated formally, but it is seems sensible that close communication about the process of care and discussion about individual agency responsibilities would ensure a consistent response. The forums are also well placed to respond to sudden changes in a service that has an impact on victims of domestic violence.

\section{CONCLUSIONS}

It is highly likely that emergency physicians will come across victims of domestic violence in their daily practice. At present, screening is not justified, though inquiry when there is suspicion by a physician is appropriate. Patients who disclose domestic violence should be offered contact with the police and help with this from the safety of the emergency department.

\section{Box 2 General advice for clinicians dealing with domestic violence}

- Domestic violence is often not disclosed to medical or nursing staff.

- Domestic violence affects both men and women.

- Interviewing patients alone increases the chances of detection of domestic violence.

- If a patient discloses domestic violence then the possibility that there are children at risk should be considered.

- It should be explained to victims of domestic violence that assault is illegal and unacceptable.

- Contact with the police and voluntary organisations should be offered from the safety of the emergency department.
Future research should aim to describe the epidemiology of domestic violence and further evaluate the effectiveness of interventions. It is through these areas that the quality of care of victims of domestic violence can be improved.

\section{Authors' affiliations}

A Boyle, Department of Emergency Medicine, Peterborough District Hospital, Peterborough, UK

S Robinson, P Atkinson, Department of Emergency Medicine, Addenbrooke's Hospital, Cambridge, UK

\section{REFERENCES}

1 Morrison LJ. The battering syndrome: A poor record of detection in the emergency department. J Emerg Med 1988;6:521-6.

2 Department of Health. Domestic violence: a resource for healthcare professionals. London: HMSO, 2000.

3 American College of Emergency Physicians. Emergency medicine and domestic violence. Dallas: American College of Emergency Physicians, 1996.

4 British Association for Accident and Emergency Medicine: academic committee. Domestic violence: recognition and management in accident and emergency. London: BAEM, 1993.

5 Mcleod M. Women against men: an examination of domestic violence based on analysis of official data and national victimization data. Justice Quarterly 1984: 170-93.

6 Coker AL, Derrick C, Lumpkin JL. Intimate partner violence among men and women - South Carolina 1998. MMWR 2000;49:691-4.

7 Tham SW, Ford TJ, Wilkinson DG. A survey of domestic violence and other forms of abuse. Journal of Mental Health 1995;4:317-21.

8 World Health Organisation. Global consultation on violence and health world report on violence and health. Geneva: WHO, 1996.

9 Mirrlees-Black C. Domestic violence: findings from a new British crime survey self completion questionnaire. London: Home Office Publications, 1999:1-136.

10 Abbott J, Johnson R, Koziol-McLain J, et al. Domestic violence against women: Incidence and prevalence in an emergency department population. JAMA 1995;273:1763-7.

11 Boyle AA, Todd CJ. Domestic violence in a UK emergency department: an incidence and prevalence survey. Emerg Med J 2003;20:438-42.

12 Dearwater SR, Coben JH, Campbell JC, et al. Prevalence of intimate partner abuse in women treated at community hospital emergency departments. JAMA 1998;280:433-8.

13 Wright J, Kariya A. Characteristics of female victims of assault attending a Scottish accident and emergency department. J Accid Emerg Med 1997; 14:375-8.

14 Fothergill N, Hashemi K. A prospective study of assault victims attending a suburban A\&E department. Arch Emerg Med 1990;7:172-7.

15 Spedding RL, McWilliams M, McNicholl BP, et al. Markers for domestic violence in women. J Accid Emerg Med 1999;16:400-2.

16 Bates L, Redman S, Brown W, et al. Domestic violence experienced by women attending an accident and emergency department. Aust J Public Health 1995; 19:293-9.

17 De Vries RM, March L, Vinen J, et al. Prevalence of domestic violence among patients attending a hospital emergency department. Aust N Z J Public Health 1996;20:364-8

18 Roberts GL, O'Toole BI, Raphael B, et al. Prevalence study of domestic violence victims in an emergency department. Ann Emerg Med 1996;27:747-53.

19 Kyriacou DN, Anglin D, Taliaferro E, et al. Risk factors for injury to women from domestic violence. N Engl J Med 1999;341:1892-8.

20 Gelles RJ. Violence and pregnancy:are pregnant women at greater risk? J Marriage Fam 1988;50:841-7.

21 McGrath ME, Hogan JW, Peipert JF. A prevalence survey of abuse and screening for abuse in urgent care patients. Obstet Gynaecol 1998;91:511-14.

22 Gielen AC, O'Campo PJ, Campbell JC, et al. Women's opinions about domestic violence screening and mandatory reporting. Am J Prev Med 2000;19:279-85

23 Gazmararian JA, Lazorick S, Spitz AM, et al. Prevalence of violence against pregnant women. JAMA 1996;275:1915-20.

24 Bergman B, Brismar B. A 5-year follow-up study of 117 battered women. Am J Public Health 1991;81:1486-9.

25 Wadman MC, Muelleman RL. Domestic violence homicides: ED use before victimization. Am J Emerg Med 1999;17:689-91.

26 Kellerman A, Mercy J. Men, women and murder: gender-specific differences in rates of fatal violence and victimization. J Trauma 1992;33:1-5.

27 Horon IL, Cheng D. Enhanced surveillance for pregnancy-associated mortality-Maryland, 1993-1998. JAMA 2001;285:1455-9.

28 Norton R, Morgan M. Mortality from interpersonal violence in Great Britain. Injury 1989;20:131-3.

29 Home Office. Homicide statistics. http://www.homeoffice.gov.uk/rds/ pubsintrol.htm

30 Chief Medical Officer. Report on confidential enquiries into maternal deaths in the United Kingdom 1997-1999. http://www.archive. official-documents.co.uk/document/doh/wmd/wmd-hm.htm

31 Gayford J. Wife battering, a preliminary survey of a 100 cases. BMJ $1975 ; 1: 194-7$ 
32 Berrios DC, Grady D. Domestic violence: Risk factors and outcomes. West J Med 1991; 155:133-5.

33 Duffy SJ, McGrath ME, Becker BM, et al. Mothers with histories of domestic violence in a pediatric emergency department. Pediatrics 1999:103:1007-13

34 Ward L, Shepherd J, Edmond AM. Relationship between adult victims of assault and children at risk of abuse. BMJ 1993;306:1101-2.

35 Muelleman RL, Lenaghan PA, Pakieser RA. Battered women: injury locations and types. Ann Emerg Med 1996;28:486-92.

36 Fanslow JL, Norton RN, Spinola CG. Indicators of assault-related injuries among women presenting to the emergency department. Ann Emerg Med 1998;32:342-8.

37 Ochs $\mathrm{H}$, Neuenschwander $M$, Dodson T. Are head, neck and facial injuries markers of domestic violence. J Am Dental Assoc 1996;127:757-61.

38 Council on ethical and jucidial affairs. AMA. Physicians and domestic violence: ethical considerations. JAMA 1992;267:3190-3.

39 Council on scientific affairs AMA. Violence against women. JAMA 1992;267:3184-9

40 Ramsay J, Richardson J, Carter $Y$, et al. Should health professionals screen for domestic violence? BMJ 2002;325:314-27.

41 Hayden SR, Barton ED, Hayden M. Domestic violence in the emergency department: How do women prefer to disclose and discuss the issues? J Emerg Med 1997; 15:447-51.
42 Feldhaus KM, Koziol-McLain J, Amsbury HL, et al. Accuracy of 3 brief screening questions for detecting partner violence in the emergency department. JAMA 1997;277:1357-61.

43 Larkin GL, Hyman KB, Mathias SR, et al. Universal screening for intimate partner violence in the emergency department: importance of patient and provider factors. Ann Emerg Med 1999;33:669-75.

44 Sugg NK, Inui T. Primary care physicians response to domestic violence: opening Pandora's box. JAMA 1992;267:3157-60.

45 Sachs CJ, Peek C, Baraff $\sqcup$, et al. Failure of the mandatory domestic violence reporting law to increase medical facility referral to police. Ann Emerg Med 1998;4:488-94.

46 Gerbert B, Caspers N, Bronstone A, et al. A qualitative analysis of how physicians with expertise in domestic violence approach the identification of victims. Ann Intern Med 1999;131:578-84.

47 Willson P, McFarlane J, Lemmey D, et al. Referring abused women: does police assistance decrease abuse? Clin Nurs Res 2001;10:69-81.

48 Sullivan CM, Bybee D, I. Reducing violence using community-based advocacy for women with abusive partners. J Consult Clin Psychol 1999;67:43-53.

49 Holt VL, Kernic MA, Wolf ME, et al. Do protection orders affect the likelihood of future partner violence and injury? Am J Prev Med 2003;24:16-21.

50 Holt VL, Kernic MA, Lumley T, ef al. Civil protection orders and risk of subsequent police-reported violence. JAMA 2002;288:589-94. 